\title{
La guerra civil española contada por el fascismo italiano: el caso del periódico infantil de Mussolini, II Balilla
}

institucional.us.es /ambitos/

\section{Lucía Ballesteros Aguayo}

Universidad de Málaga

lucia_periodista@hotmail.com

English Version: The Spanish Civil War according to Fascist press: Case in the children's newspaper II Balilla of the National Fascist Party

\section{Resumen}

La guerra civil española es uno de los episodios más relevantes del siglo XX, no sólo por la magnitud que adoptó el conflicto durante los tres años de enfrentamientos, sino también por la dimensión internacional que adquirió con la participación de

Alemania e Italia. Con frecuencia, su estudio se ha acometido desde la óptica española, y desde la prensa adulta. Es, pues, necesario el abordaje científico de la cobertura periodística que realiza el principal órgano de propaganda del Partido Nacional Fascista, el semanario infantil // Balilla, con el fin de profundizar en el conocimiento científico de nuestra historia.

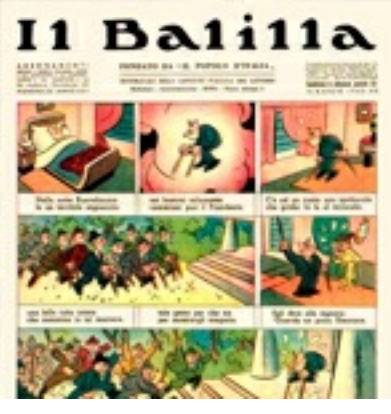

\section{Palabras clave}

Guerra civil, fascismo, prensa infantil, I/ Balilla, propaganda.

Abstract

The Spanish civil war is one of the most relevant event of the $20^{\text {th }}$ century, not only because of the magnitude that the conflict entailed, for three years of clashes, but also due to the international dimension that it acquired with the participation of Germany and Italy. Often this study has been undertaken from the Spanish perspective and from the adult press. Thus it is necessary that the main means of propaganda of the National Fascist Party, children's weekly newspaper // Balilla, carries out a scientific approach in the press coverage. To this end, we will deepen the scientific knowledge of our history.

Keywords

Spanish Civil War, fascism, Children's press, I/ Balilla, propaganda.

\section{INTRODUCCIÓN}

Nos proponemos abordar la cobertura periodística de la guerra civil española en la prensa italiana de Mussolini, en concreto, la visión partidista que ofrece en sus páginas el mayor mecanismo de propaganda fascista, el periódico infantil /l Balilla (01), órgano de comunicación del Partido Nacional Fascista, y, por tanto, el encargado del adoctrinamiento de los más pequeños en el partido único (02).

Los acontecimientos que se produjeron en España entre 1936 y 1939 tuvieron gran incidencia en la esfera internacional, así, resultaron clave, no sólo en el establecimiento de la política de entreguerras, sino también en la configuración estratégica de las potencias totalitarias tras el estallido de la Segunda Guerra Mundial.

Especial interés comprende el caso italiano, dada la ascendencia fascista de los órganos constitutivos del franquismo como es la Falange, lo cual se manifiesta incluso en la estructura orgánica de la organización; así, los primeros «flechas» comenzaron denominándose «balillas», en referencia a su identificación con las 
organizaciones juveniles de la Italia de Mussolini (03).

Junto a ello, los lazos de unión entre ambos países del Mediterráneo, establecía una preferencia por las cuestiones relacionadas con España, de manera que la participación italiana con el envío del «Corpo Truppe Volontarie» (04) fue interpretada por la prensa fascista como parte del proyecto político de Mussolini, quien aspiraba a la fascistizzacione de Europa (05), y, con ello, a la integración de España en el plan de expansión del fascismo (06).

Esta estrategia política se canalizó a través de la prensa como medio por excelencia de la propaganda totalitaria, y de los órganos oficiales del partido único (07). Entre ellos destaca la acción mediática desarrollada por II Balilla, que se presenta como modelo paradigmático de la prensa totalitaria (08), clave para entender los elementos constitutivos del discurso oficial (09).

A través de un estudio sistemático mediante el uso del método científico se ha acometido el análisis del contenido de las colaboraciones en las que se traslucen los acontecimientos relacionados con España durante 1938 y 1939 -siendo estos dos años esenciales en el desenvolvimiento del conflicto-.

La delimitación de la investigación a la prensa destinada a los más pequeños se explica por la trascendencia que el fascismo concede a la formación de las nuevas generaciones, puesto que representaban el futuro del país y la continuidad del régimen fascista. Por tanto, la concepción totalitaria de Italia implicaba una atención especial a la instrucción de los más jóvenes, de manera que cualquier iniciativa destinada a este tipo de público constituía una prioridad para el Duce. Esto se tradujo en una mayor dotación de recursos materiales y estructurales a periódicos como // Balilla o Gioventù in armi, y un singular tratamiento a otros medios de origen católico como // Vittorioso, que estaban impulsados por organismos como Acción Católica.

En suma, la guerra civil española desempeñó un papel esencial en la estrategia propagandística del líder italiano sirviendo de gran estímulo, tanto en lo personal, ya que supuso la vuelta de Mussolini a la actividad periodística (10), como en lo político, dadas las coincidencias ideológicas con el bando nacional y la rentabilidad mediática que proporcionaba la interpretación fascista del conflicto español.

Así, en el caso concreto del discurso periodístico de /l Balilla, son habituales las alusiones a la unión entre el pueblo italiano y el español, la conversión de mitos y leyendas como el Cid Campeador, la ritualización de los acontecimientos militares, las referencias a la simbiosis lingüística entre España e Italia, la estigmatización del enemigo ruso, la reconstrucción de la Roma imperial y del proyecto mundial del imperio romano, etc.

Por tanto, el apoyo del gobierno italiano a la causa franquista no sólo se materializó en el envío de tropas, sino que al mismo tiempo se llevó a cabo una intensa campaña propagandística destinada a presentar una interpretación partidista de los hechos. De manera que el discurso de I/ Balilla se fundamenta en la visión mitologizante de los episodios bélicos, y una fascistizzacione del conflicto español.

\section{JUSTIFICACIÓN}

El estudio de la prensa italiana destinada al público infantil durante los años 1938 y 1939 representa un avance en el conocimiento de la estrategia comunicativa de los regímenes fascistas, en concreto del discurso mediático que estableció Mussolini en la interacción social con la infancia (11).

El hecho de inculcar los principios ideológicos en los más pequeños constituye una de las prioridades de cualquier sistema totalitario, puesto que se presenta como una de las fórmulas más eficaces para asegurar la perdurabilidad del status quo. Así el uso que realiza el gobierno fascista italiano del periódico /l Balilla representa un ejemplo paradigmático de la gestión de la comunicación en los gobiernos totalitarios de la época.

Del mismo modo, los resultados obtenidos a partir del trabajo de campo aportan una particular concepción de uno de los hitos en la historia de entreguerras como es el conflicto civil en España.

Por tanto, el motivo que nos ha llevado a abordar esta investigación se explica por tres razones. Primero, por la 
relevancia mundial que adquiere el conflicto español en el escenario internacional, entendido como uno de los acontecimientos clave para comprender los años precedentes a la Segunda Guerra Mundial; asimismo, se trata de un suceso político e histórico que actúa de forma determinante en la historia posterior de España y en el pasado más reciente de nuestro país.

Segundo, por la trascendencia que adquiere la prensa a finales de los años 30 y principios de los 40 como el único medio capaz de llegar a grandes capas de población, siendo el canal por excelencia de los gobiernos fascistas para transmitir su mensaje ideológico, y como parte esencial del aparato propagandístico del Estado (12). Es preciso señalar la importancia que los líderes autoritarios concedieron a la prensa, controlando minuciosamente la política informativa, y ejerciendo una censura férrea sobre cualquier tipo de expresión escrita (13).

Así, la comprensión de los procesos de mediatización y de los elementos del discurso periodístico presentes en las páginas de un medio como // Balilla,contribuyen a profundizar en el uso del medio impreso durante este periodo, y a ampliar las claves de la perspectiva comunicativa implantada por Italia y España. Al mismo tiempo aporta un mayor conocimiento de la estructura de la prensa en ambos países, y proporciona algunos elementos sobre la afinidad ideológica existente entre el fascismo y el franquismo.

Y, tercero, la significación del periódico /l Balilla en el espacio interno de Italia, ya que se conformó como uno de los medios de propaganda clave en la estrategia de comunicación y adoctrinamiento de la infancia llevada a cabo por Mussolini. Su estudio nos permite, por una parte, descubrir la cosmovisión que ofrece el régimen italiano sobre la realidad a los más pequeños, y por otra, la interpretación partidista que éste realiza sobre la guerra civil española.

En este sentido, la acción mediática iniciada por la prensa fascista ejerció gran influencia sobre las relaciones diplomáticas entre Franco y Mussolini, que se afianzaron a partir del final del conflicto en 1939 (14), al mismo tiempo que contribuyó a la construcción de determinadas identidades nacionales y a la extensión del proyecto totalitario (15). No en vano, tal y como afirma Bermejo Sánchez, "es necesario que se estudien en profundidad aspectos como el que aquí se ha tratado, que pueden mostrar cómo el Franquismo poseyó en determinados momentos potencialidades - y la voluntad - para avanzar hacia un modelo de totalitarismo extremo. Y el control de toda expresión pública de pensamiento no es precisamente un aspecto secundario. Está por demostrar que fuera algo distinto de la derrota del Eje en la Segunda Guerra Mundial lo que corrigió esas tendencias [...]" (16).

\section{OBJETIVOS}

Los objetivos que nos hemos propuesto alcanzar con este trabajo pretenden dar respuesta a cuestiones que ya han sido planteadas por la comunidad científica, tales como cuáles son las principales características que adquiere la prensa infantil en gobiernos totalitarios, cómo se define la estrategia de comunicación fascista con la infancia en el contexto de entreguerras, cómo se estructura la prensa en el ámbito de los regímenes fascistas y cuáles son los principales organismos que se encargan de controlar y financiar este tipo de periódicos, en qué medida repercuten los sucesos históricos y políticos sobre el mensaje periodístico, y cuáles son las referencias presentes en el discurso periodístico de los medios italianos con respecto a los acontecimientos que se estaban sucediendo en España (17).

Debido a una serie de factores, como es el límite de espacio, la extensión reducida del artículo científico, así como la numerosa bibliografía existente, nos proponemos:

1. Analizar las características del discurso de // Balilla con respecto a la guerra civil española.

2. Definir la cobertura mediática que concede /l Balilla al caso español entre 1938 y 1939.

3. Determinar las propiedades textuales que adquiere el mensaje periodístico con respecto al conflicto español.

4. Valorar las peculiaridades que adquiere el discurso de propaganda fascista destinado a la infancia y la juventud. 
5. Delimitar la función que desempeña la guerra civil española en la estrategia de propaganda fascista.

6. Ampliar el conocimiento de la cosmovisión ofrecida a los más pequeños por parte de los órganos de comunicación oficiales del fascismo.

\section{METODOLOGÍA}

La metodología utilizada en el este trabajo es el análisis de contenido, con especial atención al contexto de los datos -ya que nos encontramos en una situación sociopolítica de preguerra mundial, y por tanto las condiciones pragmáticas de la comunicación son especialmente relevantes-, que nos permita formular inferencias acerca del significado simbólico del contenido publicado por I/ Balilla durante los años 1938 y 1939 (18).

El análisis de contenido se propone como el método más apropiado en este caso, ya que contribuye a generar mayor conocimiento acerca del objeto de estudio, y permite la aplicación de reglas sistemáticas que faciliten posteriormente la réplica de los resultados de dicha investigación. Para esta labor, y teniendo como marco la ficha de contenido que adjuntamos al final del estudio, tomamos como punto de partida el mensaje, esto es, el contenido de una información archivada.

Asimismo, en nuestro estudio se emplea la metodología inductiva mediante la cual, a partir de unos datos observados -los textos publicadas por el periódico /l Balilla acerca de los hechos de la guerra civil española-, se realiza una generalización que explica las relaciones entre los objetos observados -ya que nos permite alcanzar una interpretación general sobre la interpretación fascista de dicho acontecimiento histórico-.

Se trata, pues, de un análisis convergente en el que se integran los elementos propiamente históricos, determinados por el panorama político de entreguerras, y los aspectos estrictamente mediáticos, caracterizados por el predominio del mensaje persuasivo, con carga emocional, y fuertemente tendencioso (19).

\subsection{Muestra}

El proceso de recogida de los datos ha sido posible gracias una estancia de investigación en Roma en la que se ha podido acceder a los fondos hemerográficos de la Biblioteca Nacional de Roma, la Biblioteca de Historia Moderna y Contemporánea y el Instituto Nacional de Documentación, Innovación e Investigación educativa (INDIRE) de Florencia.

A través de la consulta de los archivos documentales se logró recopilar la totalidad de los números publicados por el periódico oficial del Partido Nacional Fascista, // Balilla, entre 1938 y 1939. En total, los dos años de edición, teniendo en cuenta que presenta una periodicidad semanal, se correspondían con 96 ejemplares, de los cuales 20 contienen colaboraciones que hacen referencia a la guerra civil española, en concreto 13 se publican en 1938, y los 7 restantes en 1939.

Por tanto, la selección de la muestra se ha realizado a partir del rastreo sistemático del contenido de la publicación a lo largo de los dos años en busca de alguna referencia a España. De manera que este periodo, que a su vez coincide con la etapa pre-bélica y la de mayor intensidad militar en suelo español, se establece como paradigma de la propaganda fascista de corte imperialista que instrumentaliza el caso español para expandir el concepto de la fascistizzacione.

Se trata, pues, de un muestreo estratégico mediante el cual se ha seleccionado una muestra de 20 ejemplares, siguiendo como criterio la presencia de una temática referente a España. El tamaño muestral con respecto al total de las ediciones correspondientes al periodo estudiado, 20 de 96 números que suman las ediciones de los dos años, evidencia la trascendencia que ocupa el conflicto de España en la estructura temática del semanario, de manera que las alusiones a la guerra civil son constantes y regulares (20).

La siguiente etapa metodológica consiste en establecer la correspondencia entre las 20 unidades de recogida y los 22 textos o unidades de análisis, de manera que existen unidades de recogida que contienen más de una 
unidad de análisis, esto es, hay ejemplares que poseen más de un texto en el que se hace alusión al enfrentamiento civil en España.

\subsection{Ficha de análisis de contenido}

La última instancia metodológica comprende la aplicación de una ficha de contenido que se ha elaborado específicamente para el objeto de estudio y que contiene las propiedades más destacadas de los textos seleccionados, de manera que a través del análisis descriptivo-analítico se puede observar la presencia/ausencia de un conjunto de variables y/o constantes en las colaboraciones seleccionadas. Estas variables, a su vez, están integradas por varias opciones categoriales o propiedades (21) que aparecen, bien de manera expresa, o bien de forma implícita en el componente textual y visual, y que se han establecido por ser exhaustivas y mutuamente excluyentes (22).

La ficha de contenido incluye las siete variables que se han aplicado a cada una de las unidades de análisis, y éstas, a su vez, están conformadas por un conjunto de categorías, de manera que cada categoría observada representa un 1, mientras que su ausencia se identifica con un 0 . Así, la suma total que obtiene cada categoría al final del análisis - una vez se ha aplicado la ficha de análisis a los 22 textos-, indica la propiedad que predomina en cada una de las variables, y por tanto, delimita las características del semanario infantil.

El resultado final, después de que se haya realizado el análisis de contenido a partir de la observación de las siete variables en cada uno de los textos, nos descubre los principales rasgos del discurso periodístico de /l Balilla.

\section{RESULTADOS DEL TRABAJO DE CAMPO}

El análisis de contenido amplía la información descriptiva del semanario infantil del partido fascista aportando importantes descubrimientos relativos a: la cobertura que realiza de los acontecimientos en España, los elementos caracterizadores del mensaje de la propaganda fascista, las peculiaridades que adquiere el discurso totalitario destinado a la infancia y la juventud, la cosmovisión que se ofrece a los más pequeños a través de la prensa, la temática recurrente, el esquema compositivo, el paradigma al que responden los personajes, las propiedades explícitas e implícitas inherentes al texto, la naturaleza de la ilustración, la firma del autor y su profesión, etc.

Según la interpretación de los datos existe un predominio del género narrativo $(72,7 \%)$, frente a las propuestas poéticas $(9,1 \%)$, y las que adoptan el formato del cómic (18,2\%). Así pues, el argumento ficcional es la opción que predomina en el corpus de textos analizados, esto es, la prensa fascista se sirve de la posibilidades creativas de la trama narrativa para construir un discurso propagandista y profundamente tendencioso, en el que destacan los elementos mitológicos, la recreación utópica de los acontecimientos bélicos, y la recreación histórica de los hechos del pasado (23). Así, por ejemplo, la trama suele estar construida a partir de la evocación de sucesos, como el envío de tropas italianas $(18,2 \%)$, o la reconstrucción partidista de acontecimientos y personajes de la historia de España como el Cid Campeador (22,7\%) (24).

No en vano, la mayor parte de los textos contienen una temática representada por los hechos históricos y militares $(59,1 \%)$, seguida de los títulos que contienen un carácter lúdico $(22,7 \%)$, y aquellos que se refieren a cuestiones ideológicas y políticas (18,2\%).

Del mismo modo, los personajes se construyen a partir de figuras arquetípicas, como el prototipo del héroe, del español victorioso y del militar valiente. La heroicidad y la superioridad constituyen los principales atributos del protagonista, que se identifica con el ideal fascista, y que, por tanto, responde a un esquema de valores representados por la idea del Bien, la virtud y la conducta modélica (25). Frente a este paradigma se sitúa el enemigo ruso, rojo y comunista (26). 
produce una exaltación de los principios del fascismo. Con frecuencia se identifica la causa franquista con el fascismo, y el frente republicano, con el "odio" y lo "inmoral", en definitiva, con la idea del Mal.

Esto explica, pues, que la mayoría de los textos transmitan valores positivos $(81,8 \%)$, y, en menor parte negativos $(18,2 \%)$, siendo éstos primeros identificados con las cualidades del arquetipo fascista, mientras que los segundos se refieren al enemigo ruso. Las descalificaciones del enemigo alcanzan, en ocasiones, niveles difíciles de asimilar para el público al que iba destinado /l Balilla, tales como "infierno comunista", "lo putrefacto", etc. (27)

En el otro extremo, y frente al "terror" republicano, se localiza el fascismo destinado a proporcionar múltiples beneficios a Europa. De tal manera que el hilo argumental en común de todos los textos son las referencias a la figura del "camarada", a la grandiosidad de Italia, al pasado imperial de Roma (28), a la actuación de las tropas italianas en España (29), y a la exaltación del Duce (30).

También se produce un enaltecimiento de la causa nacional, identificando el levantamiento militar con una "cruzada antibolchevique", y los franquistas como la representación del fascismo en España. En este sentido destaca la recreación tendenciosa de los episodios bélicos, entre los que predominan las victorias alcanzadas por los nacionales (31).

La reproducción de estereotipos suele ser un procedimiento frecuente a la hora de construir la trama que, bien contribuyen al imaginario fascista, o bien se dirigen a encomiar la actuación desarrollada por las tropas de Franco. En ambos casos, el texto se construye como una enseñanza moral que debe contribuir a modelar la actitud del lector infantil, esto es, la lectura se concibe como un proceso de aprendizaje a través del cual se presentan unos modelos ficcionales de conducta que son susceptibles de ser imitados por el niño (32).

En las producciones que recrean el conflicto español, resulta frecuente la alusión a los símbolos, los lemas y los rituales franquistas (33).

Al mismo tiempo, el lenguaje está definido por su carácter militarista, violento y maniqueo $(63,6 \%)$, de manera que representa una realidad marcada por el enfrentamiento encarnizado, los saqueos, los fusilamientos, etc., en definitiva, recrea un mundo en el que el fascismo presenta la única solución (34). También se utiliza una terminología de naturaleza ideológica y política, pero en menor medida $(36,4 \%)$.

Así pues, junto al uso de un lenguaje bélico, se sitúa la interpretación belicista de los acontecimientos como una de las principales características del discurso periodístico. Por ejemplo, proliferan las menciones a las batallas y los frentes militares, a las victorias y las derrotas, a los secuestros y los fusilamientos, etc. (35), tomando siempre como referentes el ejército romano y la Roma imperial (36). Esto explica que la mayoría de las imágenes que acompañan al texto sean de naturaleza castrense $(63,6 \%)$, al tiempo que evocadoras de episodios históricos $(36,4 \%)$.

Por último, las alusiones a la relación de fraternidad entre el pueblo español e italiano son constantes, de manera que el texto se dirige a subrayar la existencia de costumbres similares, de semejanzas lingüísticas, e incluso de una apariencia física análoga (37).

Asimismo, algunos textos se dirigen a plasmar una visión arquetípica de España, en la que destaca la música y el baile como uno de los mayores atractivos del país. Esta descripción se fundamenta en prejuicios y estereotipos (38)

La mayoría de los relatos aparecen firmados $(31,7 \%)$, o sin firmar $(22,7 \%)$, y los nombres más habituales son: G. Gostini, S. Cicinnati, D.S. Miceli , V.N. Funtata y G. Tombolato.

\section{CONCLUSIONES}

Las similitudes entre la estrategia comunicativa del fascismo y la del franquismo son evidentes, ambas estrategias de propaganda se sustentan en un discurso moral, doctrinario, basado en la violencia del 
enfrentamiento militar y la recreación partidista de los acontecimientos bélicos. También comparten la alusión a sucesos históricos y personajes del pasado como recurso para identificar la grandeza de ese periodo histórico con los gobiernos totalitarios del momento.

Tanto en la prensa infantil del franquismo, como en los órganos de propaganda fascista, el relato periodístico actúa como paradigma instructivo destinado a imprimir una serie de pautas de conducta en los lectores. Además se producen constantes alusiones a determinados hechos del pasado, como es, en el caso italiano, la época de la Roma imperial, y en el caso franquista, la reconstrucción de la etapa protagonizada por los Reyes Católicos.

Otra de las constantes en el discurso oficial de Mussolini es la descripción de la realidad a partir de una lucha escatológica entre el Bien y el Mal, de manera que el mundo se divide entre "buenos", identificados con los héroes, y "malos", representados por el enemigo. No obstante, la peculiaridad que define el discurso de // Balilla es la recreación de la guerra civil española como una cuestión interna, es decir, como un escenario más dentro de la lucha del fascismo contra el enemigo ruso. Así, la causa nacional se describe como una "cruzada antibolchebique", por lo que el caso español se interpreta como parte del proyecto de fascistizzacione de Europa.

Por tanto, la mediatización del conflicto español representó una ocasión propicia para la propaganda italiana, no sólo para mostrar el apoyo de Italia a Franco, sino, sobre todo, para reafirmar la fortaleza del fascismo en el mundo, al mismo tiempo que se implantaba en el discurso periodístico un determinado esquema compositivo de carácter moral y doctrinario.

Con este trabajo contribuimos a definir las líneas generales del estudio sobre la cobertura periodística de la guerra civil española en la prensa fascista, con el deseo de proporcionar un mayor conocimiento científico acerca de acontecimientos clave en nuestra historia más reciente. Esperamos que esta investigación sirva como punto de partida para estudios posteriores en los que se acometa el análisis del conflicto español desde la perspectiva fascista, con la singularidad que comportan los soportes destinados a la infancia. Por tanto, se abre a partir de ahora un campo de trabajo que pretendemos sea prolífero y enriquecedor.

\section{REFERENCIAS BIBLIOGRÁFICAS}

ABRIL, G. (1997): Teoría General de la Información, Datos, relatos y ritos. Madrid: Cátedra.

ALTHUSSER, L. (1974): Ideología y aparatos ideológicos del Estado. Barcelona: Laia.

ÁLVAREZ, J.T. et al., (1989): Historia de los medios de comunicación en España. Periodismo, imagen y publicidad (1900-1990). Barcelona: Ariel.

Bermejo Sánchez, B. (1991): "La Vicesecretaría de Educación Popular (1941-1945): un ministerio de la propaganda en manos de Falange”, en: Espacio, tiempo y forma, nº 4, pp. 73-89.

Bertieri, c., (1989): Fumetti all'italiana: Le fiabe a quadretti (1908-1945). Roma: Comic Art.

BIESCAS, J. A. y TUÑÓN DE LARA, M. (1982): España bajo la dictadura franquista. Barcelona: Labor.

CAMPS, A. (2014): Italia en la prensa periódica durante el franquismo. Barcelona: Publicacions i Edicions de la Universitat de Barcelona.

CANNISTRARO, P. V. (1975): La fabbrica del consenso. Fascismo e mass media. Roma-Bari: Laterza.

CARR, R. y FUSI, J. P. (1979): España de la dictadura a la democracia. $2^{\mathrm{a}}$ ed. Barcelona: Planeta.

CASASÚS, J. M. (1987): Ideología y análisis de los medios de comunicación. Barcelona: Mitre.

COLLER, X. (2000): Estudio de casos (Cuadernos metodológicos, 30). Madrid: Centro de Investigaciones

Sociológicas 
CHECA GODOY, A. (1990): Historia de le prensa andaluza. Sevilla: Fundación Blas Infante.

GARCÍA BERRIO, A. y HERNÁNDEZ FERNÁNDEZ, T. (2004): Crítica literaria: iniciación al estudio de la literatura. Madrid: Cátedra.

GARCÍA GALINDO, J.A.; GUTIÉRREZ LOZANO, J.F.; SÁNCHEZ ALARCÓN, I. (Eds.), (2002): La comunicación social durante el franquismo. Málaga: CEDMA.

Genovesi, G. (1972): La stampa periodica per ragazzi da "Cuore" a Charlie Brown. Parma: Guanda.

GENTILE, E. (1993): I/ culto del littorio. La sacralizzazione della politica nell'Italia

fascista. Roma-Bari: Laterza.

GÓMEZ BLANCO, E. (1919): Historia del Periodismo. Madrid: Biblioteca Nueva.

GORDILLO, J. C. (1956): La propaganda política. Su aspecto psicológico-social. Madrid: Pylsa.

GUBERN, R. (1974): El lenguaje de los cómics. Barcelona: Península.

Igartua, J.J., y HUMANES, M.L., (2004): Teoría e investigación en comunicación social. Madrid: Síntesis.

KRIPPENDORFF, K. (1990): Metodología de Análisis de Contenido . Barcelona: Paidós.

LAZO, A. (1995): La iglesia, la falange y el franquismo (un estudio sobre la prensa española de posguerra) . Sevilla: Universidad de Sevilla.

LOPARCO, F. (2011): I bambini e la guerra. II Corriere dei Piccoli e il primo Conflitto Mondiale (1915-1918). Firenze: Nerbini.

LORENTE, J. C. (2000): Los tebeos que leía Franco en la Guerra Civil (1936-1939). Madrid: Imphet.

Meda, J. (2007): Stelle e strips. La stampa a fumetti italiana tra americanismo e antiamericanismo (1935-1955). Macerata: Edizioni Simple.

-(2001): "Il Corriere va alla guerra. L'immaginario del Corriere dei Piccoli e le guerre del Novecento (19121943)", Storia e Documenti, n 6, 2001, pp. 97-114.

MORDADIELOS, E. (2000): La España de Franco (1939-1975): Política y sociedad. Madrid: Síntesis.

Murialdi, P. (1986): La Stampa del regimen fascista. Roma-Bari: Laterza.

PIZARROSO QUINTERO, A. (1990): Historia de la propaganda (Notas para un estudio de la propaganda política $y$ de «guerra»). Madrid: EUDEMA.

RODRIGO ALSINA, M. (1995): Los modelos de la comunicación. Madrid: Tecnos.

Sánchez Aranda, J.L. y Barrera, C. (1992): Historia del periodismo español: desde sus orígenes hasta 1975. Pamplona: Ediciones Universidad de Navarra.

Sevillano Calero, F. (1998): Propaganda y medios de comunicación en el franquismo (1936-1951). Alicante: Publicaciones de la Universidad de Alicante.

SINOVA, Justino (1989): La censura de prensa durante el franquismo. Madrid: Espasa Calpe.

\section{OTRO RECURSOS:}

Fuentes hemerográgicas 
Biblioteca Nazionale Centrale di Roma

Istituto storico della Resistenza

Biblioteca di Storia Moderna e Contemporanea di Roma

Istituto Nazionale di Documentazione, Innovazione e Ricerca Educativa (INDIRE)

Biblioteca Nacional de España

Hemeroteca Municipal de Madrid

(01) II balilla comenzó a imprimirse en 1922 en Siena por la editorial "Italia per Italia”. Un año más tarde, el 18 de febrero de 1923, inició su edición bajo la casa milanesa "Imperia" con el nombre de Il Giornale dei Balilla. Dos años después, en 1925, se convirtió en el medio infantil por excelencia de la propaganda fascista, cuando comenzó a imprimirse como suplemento de /l Popolo d'Italia (órgano del Partido Nacional Fascista fundado en 1914 por Mussolini). Por último, en 1931, ejerció como soporte oficial de la "Opera Nazionale Balilla" (organización juvenil del Partido Nacional Fascista a través de la cual se canalizaba la educación formal de los niños de entre 4 y 18 años), y, a partir de 1940, como semanario de la "Gioventù Italiana del Littorio" (organización fascista fundada en octubre de 1937 y destinada al encuadramiento civil de la juventud).

(02) Desde su nacimiento como periódico fascista, hasta su desaparición, el 27 de junio de 1943, // Balilla desempeñó un relevante papel en el proceso de adoctrinamiento de la infancia, siendo uno de los principales mecanismos de propaganda del fascismo. La orientación totalitaria y la educación patriótica eran los elementos que definieron la línea editorial del periódico infantil durante sus más de veinte años de trayectoria. Al respecto, son ilustradoras las palabras que publicó Dino Grandi en el primer número: "Il nostro giornale è dedicato ai fanciulli italiani. questi viventi fiori della nostra razza, educati al ricordo degli eroismi compiuti da quegli altri fanciulli che andarono alle guerra cantando e fermarono l'invasore sul Piave e all'esempio di quelli che per la seconda volta salvarono l'Italia nelle vie, nelle piazze, nelle campagne, riconquistando alla Madre tutti i suoi figli. I nostri Balilla, raccolti in schiere ordinate, che saranno domani falangi animose, troveranno in queste pagine l'alimento della loro intelligenza e del loro cuore". II Balilla, n 1, el 18 de febrero de 1923.

(03) La relevancia del caso italiano en la dictadura franquista se manifestó, especialmente, en la configuración de los órganos de encuadramiento civil.

(04) En español, el "Cuerpo de Tropas Voluntarias" estaba formado por 50.000 soldados italianos, camisas negras, que Mussolini envió a España del 5 al 14 de febrero de 1937 para luchar con el bando sublevado. Se enmarca dentro de la política de colaboración y apoyo mutuo de ambos líderes. La ayuda italiana fue relevante en el desarrollo del conflicto y resulta esencial para comprender el debilitamiento del frente republicano y la posterior victoria del bando nacional. Son destacados algunos episodios como la derrota en la Batalla de Guadalajara el 23 de marzo de 1937.

(05) El concepto fascistizzazione está ampliamente extendido entre los historiadores italianos, así Paolo Muriali afirma con respecto a la incidencia de este procedimiento sobre la prensa: "Mussolini procede alla fascistizzacione integrale attraverso una operazione graduata nel tempo, a volte drástica a volte duttile, a seconda delle situazione e delle convenienze. La principale línea di fondo dell'operazione - non eliminare ma fascistizzare i maggiori quotidiani d'informazione di matrice liberale che non si erano ancora allineati al fascismo — si era già intravista quando Mussolini non era ancora il padrone incontrastato del campo". Murialdi, P. (1986): La Stampa del regimen fascista. Roma: Laterza, p.1.

(06) En cuanto a la práctica fascista sobre la prensa en Italia, conviene resaltar el carácter totalitario de mediados de los años 20 con una clara prevalencia del órgano institucional sobre cualquier tipo de manifestación impresa. Así, Murialdi afirma que "Sfruttando e gonfiando le carenze del sistema liberale dell'informazione, soprattutto come si era andato configurando nel nostro paese, attaccando «il famoso e 
famigerato Quarto potere» o definendo la libertà «un concetto astratto e inafferrabile» (Amicucci), i fascisti trovano più larghi consensi”. ibídem, pp. 6-7.

(07) Las referencias al conflicto español durante estos dos años son constantes en el periódico oficial del Partido Nacional Fascista, de manera que la actitud subyacente del soporte evidencia cierta simpatía y solidaridad con los denominados "fratelli spagnoli".

(08) El profesor Juri Meda subraya la aparición de /l Balilla como el primer órgano creado por el Duce para el aleccionamiento de la infancia, y destaca la influencia que ejerció sobre los soportes posteriores creados con el mismo propósito. Así, el semanario infantil se convirtió en paradigma de la prensa fascista, estableciendo los principios y las características formales de cualquier proyecto editorial dirigido a la infancia. Meda lo expresa de la siguiente manera: "Già nel 1922 la casa editrice senese «Italia per Italia» diede alle stampe «ll Balilla», il primo periodico fascista per ragazzi, che riproduceva sostanzialmente lo schema editoriale del «Corriere dei Piccoli», con alcune "favole a quadretti" di chiara ispirazione ideologica intervallate da testi scritti e rubriche di posta e curiosità [...] L'educazione morale e politica dei fanciulli costituiva la condizione essenziale per lo sviluppo del consenso di massa al regimen fascista". MEDA, J. (2007): Stelle e strips. La stampa a fumetti italiana tra americanismo e antiamericanismo (1935-1955). Macerata: Edizioni Simple, pp. 23-24.

(09) Además de // Balilla existían otros medios impresos destinados a los más pequeños de inspiración totalitaria. Algunos de los ejemplos más significativos fueron // Corriere dei Piccoli y Gioventù in armi. Junto a ellos destaca la actividad propagandística desarrollada por los soportes de Acción Católica, con /l Vittorioso como el prototipo de periódico religioso más influyente de la época. Para más información puede consultarse Murialdi, P., op. cit.; MEDA, J., op. cit;; o LOPARCO, F. (2011): I bambini e la guerra. II Corriere dei Piccoli e il primo Conflitto Mondiale (1915-1918). Firenze: Nerbini.

(10) La incidencia del conflicto en España tuvo tal repercusión que supuso el retorno de Mussolini a los periódicos. Este hecho testimonia la implicación del Duce en la guerra civil española, y su deseo de llevar a cabo un proceso de fascistizzacione en España similar al iniciado en Italia. Por tanto, el caso español motivó su vuelta a los periódicos -cuestión que había abandonado tiempo atrás- en la misma dirección que luego será imitada por los responsables de los medios franquistas, esto es, a través de un discurso maniqueo destinado a alimentar la defensa patriótica de los que luchaban en el bando nacional, e iniciando la llamada "crociata antibolscevica". Además, nos descubre la gran influencia que ejerció el gobierno fascista en la conformación del franquismo, especialmente en las cuestiones ideológicas y en la estructuración de los medios de comunicación.

Así, como recoge Paolo Murialdi, "La guerra de Spagna segna anche il ritorno di Mussolini all'attività giornalistica dopo una lunga pausa. La posta in campo, l'ambizione di essere il capo politico di un'Europa fascistizzata, la presenza di tanti antifascisti tra i difensori della Repubblica spagnola e, infine, il gioco diplomatico, lo attirano e lo eccitano". Murialdi, P., op. cit., p. 150.

(10) La existencia de la denominada prensa oficial en el franquismo estuvo canalizada por la red de periódicos del Movimiento Nacional, la cual es considerada por el historiador Benito Bermejo como el "mayor grupo periodístico -en número de cabeceras, si no en importancia real- de la historia de España". De tal manera que durante los primeros años de la década de los 40 casi todos los periódicos infantiles pertenecían a la cadena del Movimiento que, gracias a su extensión geográfica y a los privilegios que obtenía del Estado -tales como la exención de censura y cupos de papel preferente-, lograron una importante difusión a lo largo de todo el territorio nacional. De la misma manera en la dictadura italiana se implantaron mecanismos de centralización de la prensa en torno al partido único. Por tanto, el control de la política informativa es un factor común en los dos gobiernos totalitarios.

(11) Entre las causas que explican la supremacía de medio impreso se sitúa la facilidad para llegar a amplios sectores de la población y el estado incipiente en el que se encontraban otros medios, como la televisión, que iniciaba sus primeras emisiones a principios de los años 40, y la radio que aún no representaba un soporte de masas debido a su limitada expansión. De esta forma, los gobiernos fascistas impulsaron el utilitarismo político de las publicaciones periódicas como mecanismos de difusión del mensaje oficial. Por otra parte, se hacía necesario que la prensa ejerciera una clara función persuasiva y doctrinaria y actuara como mecanismo de legitimación del Estado fascista. Así se instaló al servicio de los objetivos ideológicos marcados por el poder. 
(12) La coincidencias de la estrategia comunicativa entre el primer franquismo y el caso italiano, así como el deseo de Franco de implantar una orientación de la prensa similar a la constituida por el régimen de Mussolini o de Hitler se extraen de las conclusiones del trabajo de Francisco Sevillano Calero en Propaganda y medios de comunicación en el franquismo (1936-1951), quien admite que "entre 1938 y 1945 la política informativa del franquismo siguió el esquema propagandístico de los regímenes fascistas en Italia y Alemania, el modelo de prensa español compartió algunos de los rasgos propios al respecto en ambos países". Sevillano Calero, F. (1998): Propaganda y medios de comunicación en el franquismo (1936-1951). Alicante: Publicaciones de la Universidad de Alicante, p.79. Al respecto, también son esclarecedoras las reflexiones de Camps, A., en Italia en la prensa periódica durante el franquismo donde advierte sobre la fascistizzacione de la prensa franquista durante los primeros años de posguerra: "Desde el final de la Guerra Civil española (y un poco antes, con la instauración de la censura de guerra) hasta 1966 (año en el que se promulga la Ley de Prensa (la llamada «Ley Fraga»), se abre una etapa que, aunque no monolítica, constituye un bloque definido en lo referente a la política cultural española, y más concretamente en lo concerniente a la censura, que afectará a las relaciones de España con los demás países de su entorno, así como a la producción del libro (que incluye las traducciones). Los primeros años de la posguerra, los llamados «años azules», muestran un singular interés del franquismo por aquellos países donde se habían implantado regímenes totalitarios. En ese proceso, la Italia fascista constituye un referente de primerísimo orden". Camps, A. (2014): Italia en la prensa periódica durante el franquismo. Barcelona: Universidad de Barcelona, p.10.

(13) Que se consolidaron en el encuentro entre los dos líderes en Bordighera, el 12 de febrero de 1941.

(14) En este contexto hay que situar el proceso de "falangización" que experimenta la sociedad española con la influencia política e ideológica de la Falange en todas las esferas de la vida. Prueba de ello fueron los numerosos organismos y asociaciones juveniles que se crearon para tal fin, esto es, para impulsar la instrucción militar y la formación moral en los principios del partido único. La creación de las diferentes estructuras en torno al partido contribuyeron a esta labor, como por ejemplo, la puesta en marcha de los sindicatos verticales, el Frente de Juventudes, las Milicias de FET y de las JONS, la Sección Femenina, etc., junto con otros mecanismos de adoctrinamiento, dieron lugar a que los primeros años de la posguerra se conocieran como la "época azul" por el predominio de la Falange sobre todas las estructuras sociales, políticas y económicas.

(15) El historiador hace referencia a este aspecto en un trabajo más amplio especializado en el estudio del organigrama de la Vicesecretaría de Educación Popular como una de las instituciones de control comunicativo, e imposición de la censura periodística de la primera mitad de la década de los 40 . Las semejanzas entre la actuación ejercida por este órgano y los mecanismos de coerción implantados por el Duce en torno al Ufficio stampa, o el posterior Minculpop (Ministero della cultura popolare), revelan ciertas constantes en el tratamiento de la prensa y en la actuación de los gobiernos fascistas sobre los medios impresos. BERMEJO SÁNCHEZ, B. (1991): "La Vicesecretaría de Educación Popular (1941-1945): un "ministerio" de la propaganda en manos de Falange", en: Espacio, tiempo y forma, n 4, pp. 73-89.

(16) La prensa como medio de propaganda alcanzó gran trascendencia en esta época, no en vano, una de las fórmulas de actuación política más relevantes era la militarización periodística, esto es, la utilización del soporte impreso como instrumento de ideologización y elemento imprescindible del plan de propaganda establecido por los regímenes totalitarios. Esto explica, a su vez, que dichas prácticas presenten múltiples similitudes de un país a otro, puesto que el denominador común que caracteriza a los gobiernos totalitarios es, entre otros aspectos, la imposición de una estricta política de control de los medios a través del partido único, la instauración de una férrea censura y la existencia de un discurso periodístico dirigido y tergiversado, en el que la realidad se presenta a partir de la exaltación de las virtudes del sistema de gobierno y de su líder, al tiempo que se produce la estigmatización del enemigo político. Por tanto, la cobertura que realiza /l Balilla de la contienda no responde a una descripción exhaustiva de los acontecimientos históricos, sino más bien se enmarca dentro de la estrategia propagandística promovida por el régimen italiano.

(17) El análisis de contenido se entiende hoy en día como el método por excelencia en los trabajos científicos sobre la comunicación mediática. Definido por Krippendorff como "una técnica de investigación destinada a formular, a partir de ciertos datos, inferencias reproducibles y válidas que puedan aplicarse a su contexto", el análisis de contenido facilita el estudio sistemático, objetivo y cuantitativo, basado en la medición de 
determinadas variables. De esta manera, y a través de la identificación de un conjunto de variables o indicadores -que bien se manifiestan expresamente en el texto, o bien subyacen de forma latente en el mismo-, es posible obtener descripciones sumarias de mensajes de distintas naturaleza. KRIPPENDORFF, K. (1990): Metodología de Análisis de Contenido. Barcelona: Paidós, p.28.

(18) En este contexto se sitúa el paradigma conductista de la comunicación, a través del cual se profundizaba en el poder de persuasión que ejercían los medios sobre los destinatarios. La aproximación behaviorista abogaba por una concepción mecanicista de la comunicación, que se establecía como un proceso lineal, mecánico y unidireccional. Esta perspectiva influyó fuertemente en la propaganda política de los años precedentes al estallido de la Segunda Guerra Mundial.

(19) Consultar Tabla nº 1. Relación de textos analizados.

(20) Consultar Tabla $n^{\circ} 2$. Variables y Categorías del análisis de contenido.

(21) La ficha de contenido aborda el análisis, tanto de los aspectos formales, en este caso el tipo de ilustración que acompaña al texto, como de las propiedades con respecto al contenido, siendo el título uno de los elementos más elocuentes y expresivos, dado su carácter tendencioso y propagandístico.

(22) Obsérvese el siguiente relato poético construido a partir de una concepción partidista y utópica de la actuación militar. Destaca también la carga emotiva que el autor imprime al lenguaje. "Gli eroi dell'Alcazar", $n^{\circ}$ 48, 27 de noviembre de 1938, p. 12: "Correvano per il mundo/Coprendosi di gloria/Ovunque riscuotendo/Superba la vittoria. [...] Oggi lavaste l'onta/E il sangue che la bagna/Resti nella memoria/Delle genti di Spagna.".

(23) Es el caso de la historia "Vita eroica del Cid" que proliferó durante 1938, publicándose un episodio nuevo de la serie en los siguientes ejemplares: $n^{\circ} 42,16$ de octubre de 1938, pp. 4 y $5 ; n^{\circ} 43,23$ de octubre de 1938, p. $11 ; n^{\circ} 44,30$ de octubre de 1938, p. 7; $n^{\circ} 46,13$ de noviembre de 1938, p. 7; no 47, 20 de noviembre de 1938, p. $11 ; y n^{\circ} 49,4$ de diciembre de 1938, p. 2

(24) Obsérvese la descripción arquetípica del protagonista, Danone, al que se le atribuyen cualidades positivas como la heroicidad y el coraje. El texto se titula "Danone in Spagna" y está publicado en el ejemplar del $n^{\circ} 7,13$ de febrero de 1938, p. 12: "Ma dalla trincea, il nostro danone dal coraggio leggendario, ha assistito alla cattura del compagno e il suo cuore gia bolle d'ira".

(25) Véase el carácter violento del siguiente texto en el que se realiza una fuerte descalificación del enemigo republicano. La estigmatización del contrario es uno de los rasgos constantes en la estrategia de propaganda fascista, pero adquiere especial relevancia por su trascendencia en los periódicos infantiles. El texto se titula "Bandiera bianca" y se publica en el no 10, 5 de marzo de 1939, p. 2: "L'insurrezione di Franco, l'insurrezione ciòe della Spagna sana, laboriosa, civile e imperitura avrebbe purgato il Paese di tutti gli elementi putrescenti, in brevissimo tempo. Senonché al risveglio delle armi spagnole, delle quali la Francia non serba un molto grato ricordo, la propaganda rossa si tramutò subito in uno sfacciato aiuto verso tutta la feccia republicana che in nome della libertà vuotava i sepolcri per fucilare gli scheletri delle monache, vuotava le case delle banche per immergersi nelle orgie, vuotava la terra che abitavano della sua essenza di Patria per venderla allo straniero".

(26) Es el caso del relato "Alle porte di Malaga", del no 33, 13 de agosto de 1939, p. 10: "Sono coloro che erano fuggiti dall'inferno comunista per nascondersi in qualche sperduto casolare di campagna [...] Gli assassini in Malaga, in sette mesi di terrore, sono stati più migliaia. Nella sola notte di Natale, per rappresaglia a un bombardamento di due trimotori nazionali, dopo una vera caccia all'uomo che non rispettò né donne né bambini, più di ottocento cadaveri restarono per le strade della città".

(27) Las referencias a la Roma imperial son constantes en la prensa fascista dentro de una estrategia de manipulación dirigida a identificar el sistema implantado por Mussolini con la grandeza del imperio romano. Esta alusión al pasado también se produce en las publicaciones infantiles del franquismo, donde aparecen constantes referencias a los Reyes Católicos o el Cid Campeador. Para más información sobre las características del discurso de la prensa infantil franquista, consúltese BALLESTEROS AGUAYO, L. (2016): Las 
revistas infantiles y juveniles de FET y de las JONS, y de Acción Católica durante la posguerra española (193853): la prensa al servicio de la legitimación del Estado franquista. Tesis inédita. Universidad de Málaga, Málaga, 2016.

(28) Obsérvese la descripción en tono jocoso que realiza el protagonista de "Usi di Spagna" sobre la vida diaria de las tropas italianas en España. El relato cuenta algunas anécdotas de los militares italianos como, por ejemplo, alguna confusión lingüística con la traducción al español. El texto está publicado en el n 23,4 de junio de 1939, p. 8: "E io attendevo che "arrivasse" presto quel "desayuno", ciò il caffelatte, ma dopo un quarto d'ora di vana attesa un lampo di genio mi fece ricordare che in spagnolo..."a riva" vuol dire "di supra". I feci appena in tempo a volare al piano superiore per raccapezzare gli avanzi...".

(29) Véase la descripción de II Duce que se realiza en "Bandiera bianca", del n 10, 5 de marzo de 1939, p. 2: "La totale redenzione della Spagna è ormai limpidamente delineata. Ancora sotto il dominio rosso languono undici provincie, ma le sorti sono già decise. II DUCE, parlando dal balcone di palazzio Venezia al mondo, lo ha espresso con una delle sue frasi scultoree lo cui si respira l'alito eterno della storia. Dal 17 luglio del 1936, quando Siviglia e Burgos spiegarono alla luce dei veri ideali latini e alla gloria del combatimento i vessilli di porpora e d'oro, al 26 gennaio del 1939, data della capitolazione di Barcellona, è tutto un susseguirsi di vittorie".

(30) Resulta elocuente la recreación partidista que realiza el suplemento de II Popolo d'Italia sobre determinados episodios militares de la guerra de España, como es la conquista de Barcelona por las tropas nacionales: "La splendida vittoria di Barcellona è un altro capitolo delle storia della nuova Europa che noi siamo creando". Ibídem, p. 10.

(31) Aquí se pone de manifiesto dos de los elementos comunes al discurso propagandístico, el uso de una terminología victoriosa, y la plasmación de una determinada visión imperial del mundo impulsada por Mussolini; de tal manera que el proyecto fascista se convierte en un eje vertebrador de la estrategia periodística, y por tanto, son numerosas las alusiones al respecto en las colaboraciones de II Balilla.

(32) Véase, por ejemplo, la apelación al lector que se realiza, tanto en “Usi di Spagna”, publicado en el $n^{\circ} 23,4$ de junio de 1939, p. 8: "Voi, balilla ginnasiali, sapete che cosa vuoi dire questa parola?", como en "Un ragazzo di Teruel", del n 51, 17 de diciembre de 1939, p. 8: "Questa è una storia vera, la storia de un ragazzo spagnolo, un ragazzo come voi che mi ascoltate. Jose Vicente infatti non aveva più di quattordici anni nel 1937, quando la guerra insanguinata la Spagna, quella lunga guerra che voi tutti avete seguito trepidanti [...]".

(33) Es el caso de "«¡Arriba España!...»", publicado en el n 39, 25 de septiembre de 1938, p. 11: "Mi avete visto poco fa, nella casa dove vi hanno interrogato...Era la nostra casa quella...,ma ora...Papá e mamma sono stati fucilati...Mio fratello...Sono solo, venite...Conosco questi luoghi...Vi condurro in salvo...Arriba España!".

(34) Este estilo violento se observa en el texto "In terra di Spagna", del n 5, 29 de enero de 1939, p. 9: "Quando seppi che l'amico Aurelio era tornato della Spagna,mi precipitai da lui [...] Una settimana, ti ho detto; una settimana di tentativi vani e cruenti: i rossi non cedevano di un palmo e s'erano fortificati da infischiarseno [sic.] per fino dall'artiglieria e degli aerei".

(35) Obsérvese, por ejemplo, la descripción violenta e irónica que realiza el autor de un fusilamiento en "«¡Arriba España!...»", del n 39, 25 de septiembre de 1938, p.11: "Il prigioniero compresse, ma non si scompose. Quando contate di fucilarmi - chiese con voce ferma. - Domattina, se non parlerete - Benissimo: spero di essere invitato io pure alla cerimonia...E non riuscirono a levargli altro di bocca".

(36) Véase, por ejemplo, la reproducción idealizada de Roma que se produce en el relato "Usi di Spagna", en la edición del $n^{\circ} 23,4$ de junio de 1939, p. 8: "Forse si vorranno degli anni pecche la Spagna torni spensierata e musicale come una volta, ma, questo è certo, quando voi balilla andrete a visitarla, la trovare disciplinata e lavoratrice, sull'esempio immortale di Roma".

(37) Sirva como ejemplo el siguiente relato en el que aparecen numerosas alusiones a las semenjanzas lingüísticas entre el español y el dialecto napolitano: "Era divertente curiosare in mezzo alle folle, leggendo le diciture dei negozi che talvolta ricordando stranamente il dialetto napoletano, e cercando di indovinane il senso". 
Idem.

(38) Obsérvese la visión estereotipada de España en el siguiente texto: "A siviglia un spettacolo mi fu offerto una sera quando, fuori della porta dell'albergo, si organizzo in quattro e quattr'otto un balletto, una "seguidilla", al suono di un "pianino", con dieci coppie di piccola ballerine". Idem.

\section{ILUSTRACIONES, FIGURAS Y TABLAS:}

\begin{tabular}{|c|c|}
\hline & 1938 \\
\hline Título del texto & n, fecha y pág. \\
\hline "Danone in Spagna" & $n^{\circ} 4,23$ enero 1938, p. 12 \\
\hline "Danone in Spagna" & $n^{0} 5,30$ enero 1938, p. 8 \\
\hline "Danone in Spagna" & $\mathrm{n}^{\circ} 7,13$ febrero 1938, p. 12 \\
\hline "Danone in Spagna" & $n^{\circ} 8,20$ febrero 1938, p. 9 \\
\hline "«¡Arriba España!...»" & $n^{0} 39,25$ septiembre 1938, p.11 \\
\hline "Vita eroica del Cid" & $n^{0} 42,16$ octubre 1938, pp. 4 y 5 \\
\hline "Sul fronte di Teruel" & $n^{\circ} 42,16$ octubre 1938, p. 11 \\
\hline "Vita eroica del Cid" & $n^{\circ} 43,23$ octubre 1938, p. 11 \\
\hline "Vita eroica del Cid" & $n^{\circ} 44,30$ octubre 1938, p. 7 \\
\hline "Vita eroica del Cid" & $\mathrm{n}^{\circ} 46,13$ noviembre 1938, p. 7 \\
\hline "Vita eroica del Cid" & $\mathrm{n}^{\circ} 47,20$ noviembre 1938, p. 11 \\
\hline "Gli eroi dell'Alcazar" & $\mathrm{n}^{\circ} 48,27$ noviembre 1938, p. 12 \\
\hline "Vita eroica del Cid" & $\mathrm{n}^{\circ} 48,27$ noviembre 1938, p. 7 \\
\hline "Vita eroica del Cid" & $n^{\circ} 49,4$ diciembre 1938 , p. 2 \\
\hline "Franco lo syogliato" & $n^{\circ} 52,25$ diciembre 1938, p. 14 \\
\hline
\end{tabular}

\begin{tabular}{ll}
\hline & 1939 \\
\hline Título del texto & $n^{\circ}$, fecha y pág. \\
\hline "Verso Santander" & $n^{\circ} 4,22$ enero 1939, p. 15 \\
\hline "In terra di Spagna" & $n^{\circ} 5,29$ enero 1939, p. 9 \\
\hline "Bandiera bianca" & $n^{\circ} 10,5$ marzo 1939, p. 2 \\
\hline "Usi di Spagna" & $n^{\circ} 23,4$ junio 1939, p. 8 \\
\hline "In terra di Spagna" & $n^{\circ} 30,23$ julio 1939, p. 14 \\
\hline "Alle porte di Malaga" & $n^{\circ} 33,13$ agosto 1939, p. 10 \\
\hline "Un ragazzo di Teruel" & $n^{\circ} 51,17$ diciembre 1939, p. \\
\hline
\end{tabular}

Tabla $n^{\circ}$ 1. Relación de textos analizados

Fuente: Elaboración propia a partir de los materiales hemerográficos recopilados en los archivos de la Biblioteca a Nazionale Centrale di Roma, el Istituto storico della Resistenza, la Biblioteca di Storia Moderna e Contemporanea di Roma, y el Istituto Nazionale di Documentazione, Innovazione e Ricerca Educativa (INDIRE) 


\begin{tabular}{|c|c|}
\hline Variables & Categorias \\
\hline \multirow{3}{*}{ Género } & Cómic \\
\hline & Narrativa \\
\hline & Poesía \\
\hline \multirow{2}{*}{$\begin{array}{l}\text { Naturaleza de las } \\
\text { imágenes }\end{array}$} & Creativa-imaginativa \\
\hline & $\begin{array}{l}\text { Hechos militares } \\
\text { Personaies } \mathrm{H}^{\mathrm{a}} \text { Esnaña }\end{array}$ \\
\hline \multirow[t]{4}{*}{ Temática } & Histórico-militar \\
\hline & Ideológico-político \\
\hline & Lúdico \\
\hline & Informativo \\
\hline \multirow{2}{*}{$\begin{array}{l}\text { Valor predominante en el } \\
\text { texto }{ }^{1}\end{array}$} & Positivo \\
\hline & Negativo \\
\hline \multirow{2}{*}{$\begin{array}{l}\text { Referencias a hechos } \\
\text { históricos }\end{array}$} & España \\
\hline & Italia \\
\hline \multirow[t]{3}{*}{ Términos frecuentes ${ }^{3}$} & Políticos-ideológicos \\
\hline & Religiosos \\
\hline & Militares \\
\hline \multirow[t]{4}{*}{ Autores } & Nombres propios \\
\hline & Sin firma \\
\hline & Anónimo \\
\hline & Siglas \\
\hline
\end{tabular}

Tabla $n^{\circ} 2$. Variables y Categorías del análisis de contenido

Fuente: Elaboración propia

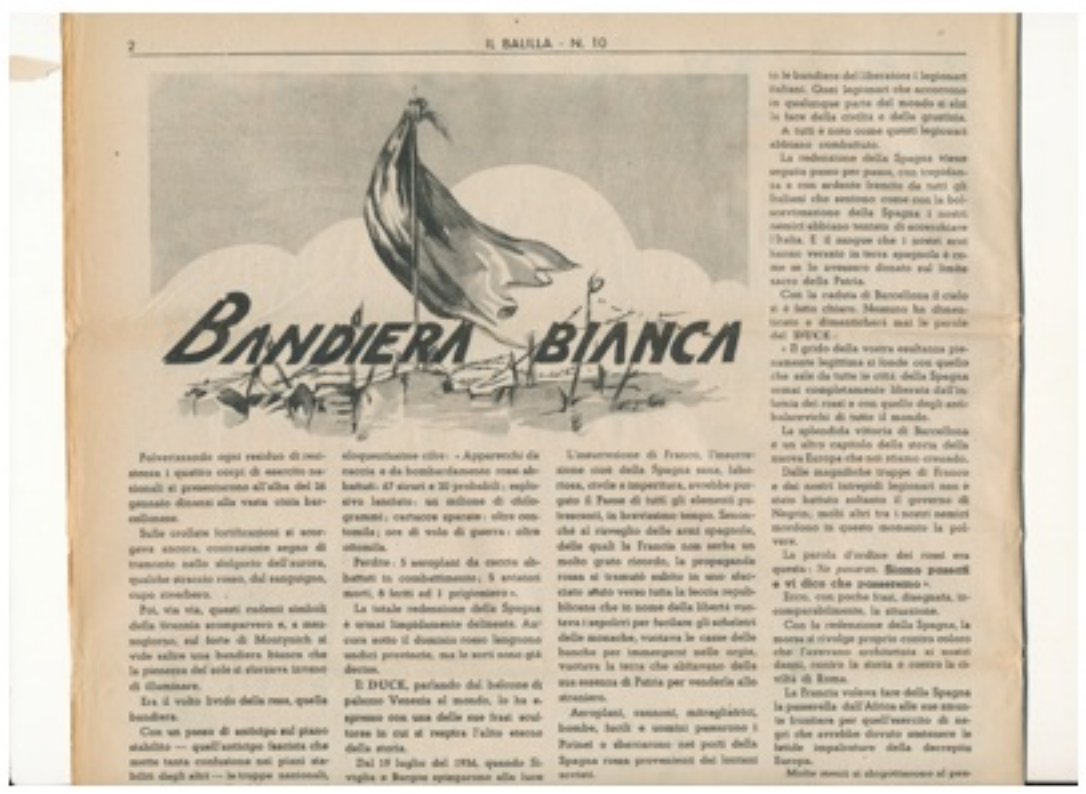

Figura $n^{\circ} 3$. "Bandiera bianca", $n^{\circ}$ 10, 5 marzo 1939

Fuente: Istituto storico della Resistenza. 


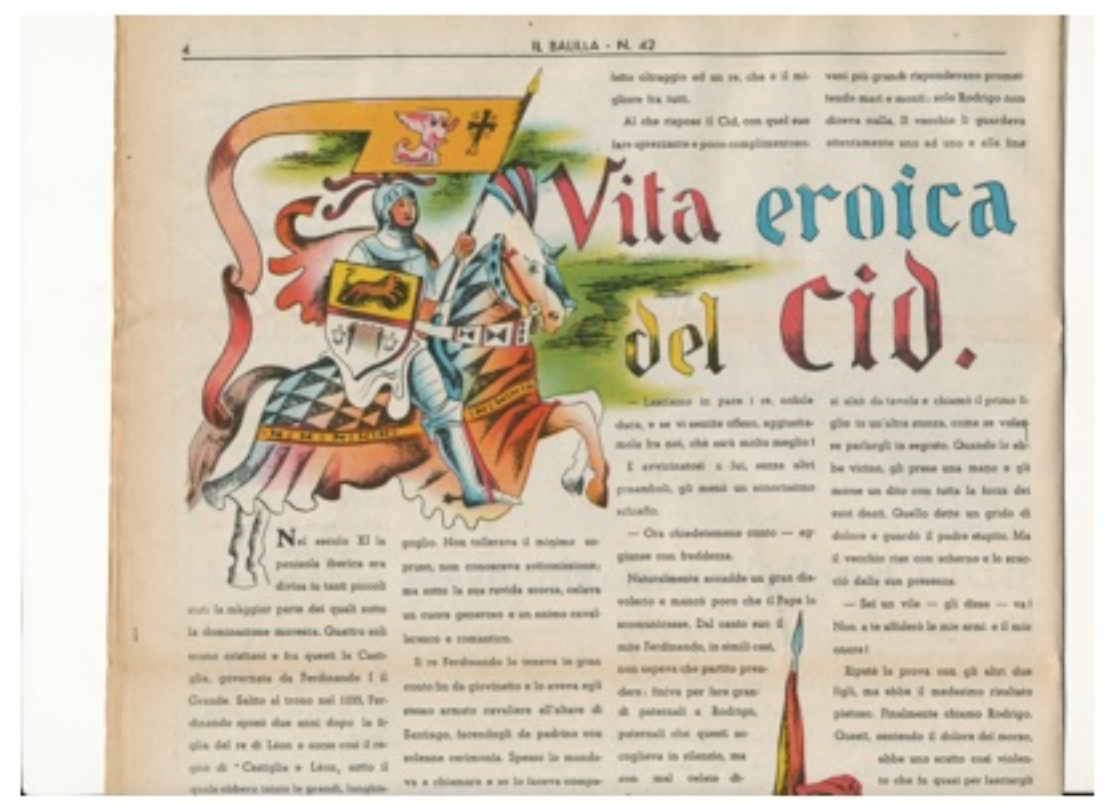

Figura n ${ }^{\circ}$. "Vita eroica del Cid", $n^{\circ} 42,16$ de octubre de 1938

Euente: Istituto storico della Resistenza.

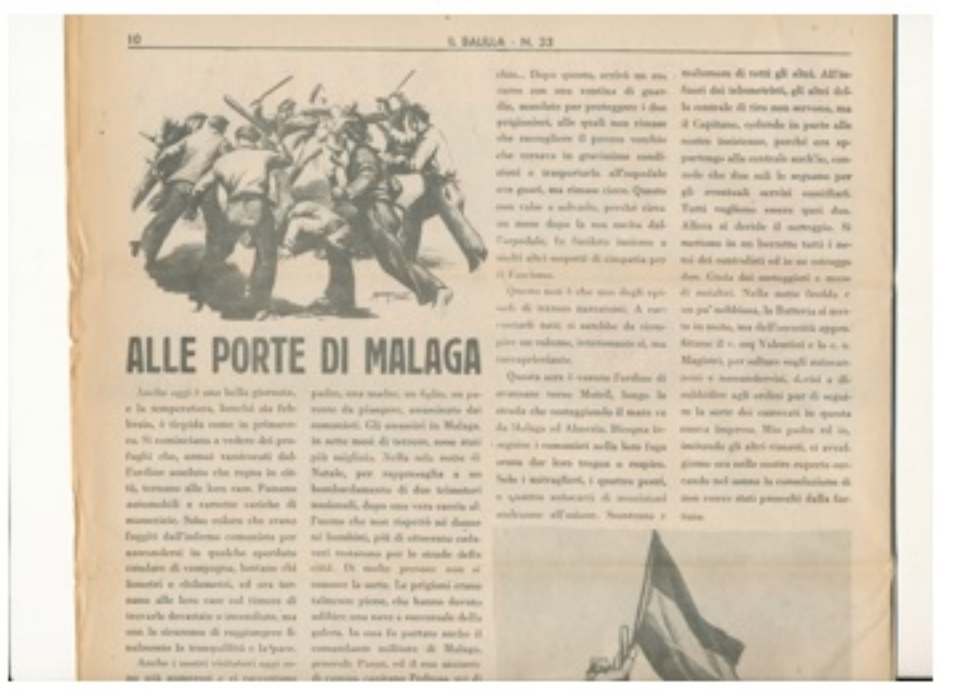

Figura $n^{\circ}$ 5. "Alle porte di Malaga", $n^{\circ} 33,13$ agosto 1939

Fuente: Istituto storico della Resistenza 


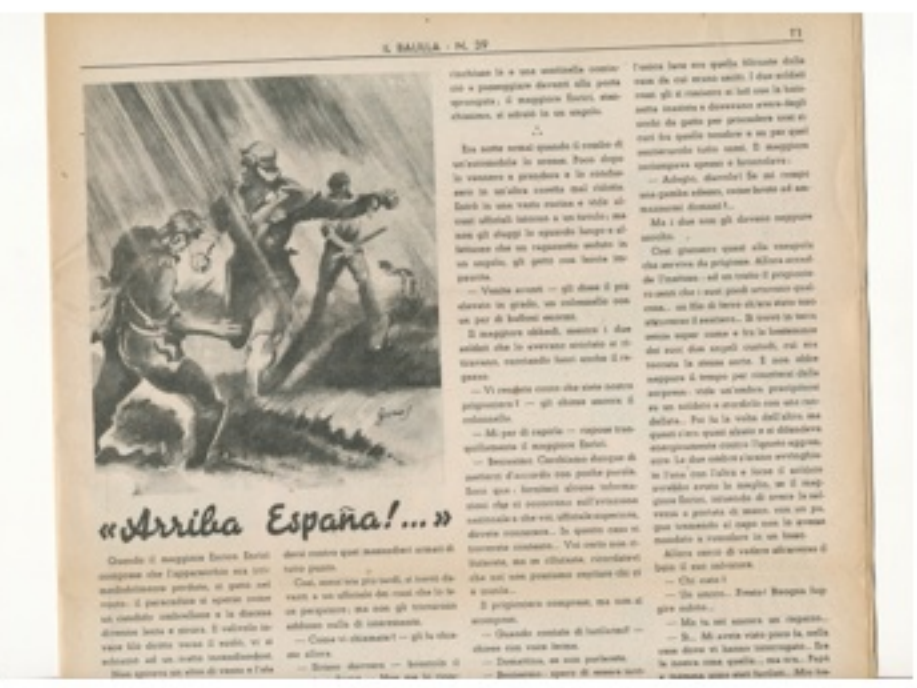

Figura n 6. "«AArriba España!...»", n 39, 25 de septiembre de 1938

Fuente: Istituto storico della Resistenza.

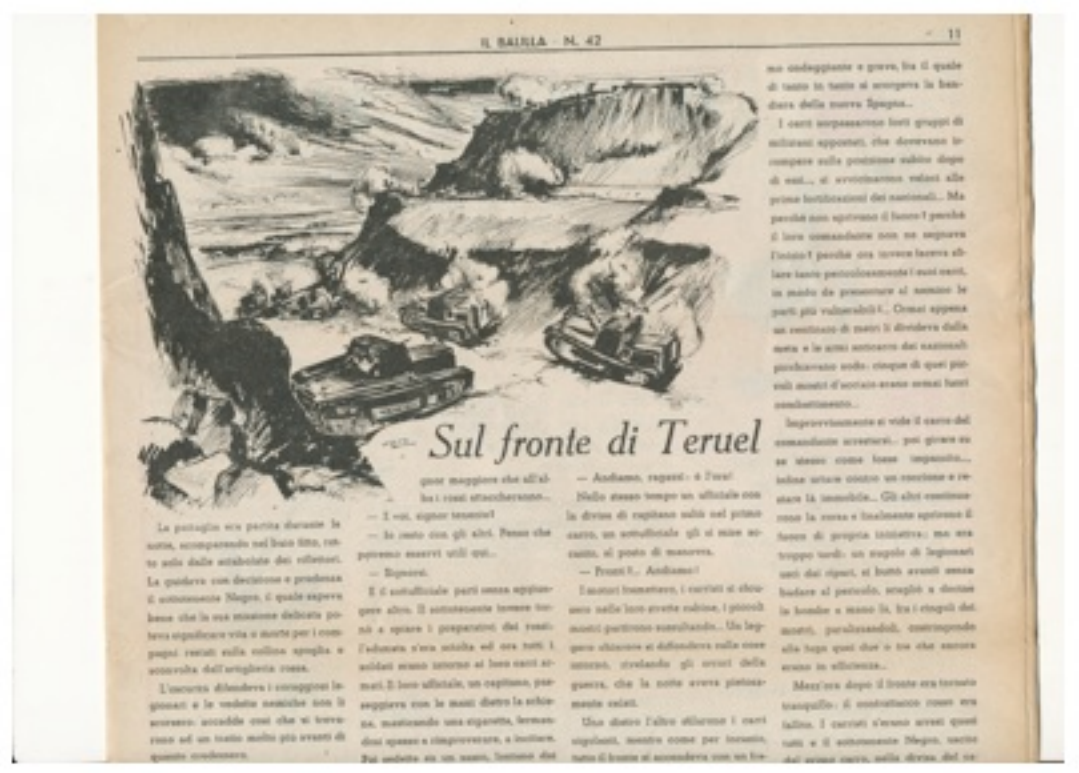

Figura $n^{\circ} 7$. "Sul fronte di Teruel", $n^{\circ} 42,16$ octubre 1938

Fuente: Istituto storico della Resistenza.

\section{BREVE SEMBLANZA DE LAAUTORA}

Lucía Ballesteros Aguayo es Licenciada en Periodismo y en Publicidad y RRPP. Especialista en prensa infantil, actualmente está finalizando su tesis doctoral Las revistas infantiles y juveniles de FET y de las JONS, y de Acción Católica durante la posguerra española (1938-53): la prensa al servicio de la legitimación del Estado franquista. Ha realizado una estancia de investigación en la Universidad de La Sapienza de Roma. 
Recibido: 01/07/2016

Aprobado: 11/09/2016 